\title{
Charge Transport and Current in Non-polar Liquids
}

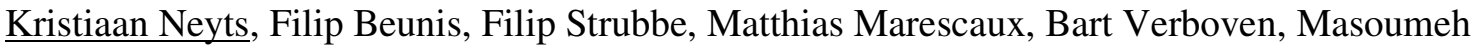 \\ Karvar \\ ELIS Department, Ghent University, Ghent, Belgium \\ E-mail: kneyts@elis.ugent.be
}

Key Words: electrophoresis, transient current, tracking

Electrophoresis in non-polar liquids has recently found a new application in paper-like displays. Colored (or black and white) charged particles move under influence of an electric field and -depending on their position in a pixel- can be visible or not for the observer of the display. Surfactant molecules are added to the non-polar liquid to charge and stabilize the particles and lead to the formation of inverse micelles. When a voltage pulse is applied, the electrical currents and fields are mainly determined by the transport of the inverse micelles.

The mechanism of drift and diffusion of inverse micelles with charge $+e$ or $-e$ in a non-polar liquid between planar electrodes, leads to complex transient currents which depend on the inverse micelle concentration, the mobility, the applied voltage and the device thickness. The comparison between simulated and measured transient currents indicates that the cited mechanisms describe the behavior quite well, even if the concentration, cell thickness or applied voltage vary over several orders of magnitude [1-4].

Tracking charged particles in a non-polar liquid with a microscope is a very sensitive method to determine the electric field and hydrodynamic motion in a non-polar liquid [5]. We have used this method to further validate the model based on drift and diffusion of charged inverse micelles. These experiments clearly show that the electric field is considerably changing as a function of time and position when an electrical voltage pulse is applied.
In addition to the motion of existing charged inverse micelles, generation and recombination can be detected experimentally from detailed current measurements [6]. Generation can occur in the bulk of the non-polar liquid when uncharged inverse micelles collide, or near the surface of the electrode layer.

The theoretical models can be applied to mixtures of different non-polar liquids and surfactant molecules between planar electrodes. Based on only a few parameters different transient phenomena can be described. The resulting understanding is important for the development of electronic ink, and it can also be used for the characterization of many kinds of colloidal particles.

Aknowledgement: The authors would like to acknowledge the IAP-VI project photon@be funded by BELSPO, the Belgian Science Policy program.

\section{References}

1. A. R. M. Verschueren, P. H. L. Notten, L. J. M. Schlangen, F. Strubbe, F. Beunis and K. Neyts, J. Phys. Chem. B. 112, 2008, 13038

2. F. Beunis, F. Strubbe, K. Neyts and A.R.M. Verschueren, Applied Physics Letters 90 2007, 182103

3. F. Beunis, F. Strubbe, M. Marescaux, K. Neyts and A.R.M. Verschueren, Applied Physics Letters 91 2007, 182911

4. F. Beunis, F. Strubbe, M. Marescaux, J. Beeckman, K. Neyts, and A. R. M. 
Verschueren PHYSICAL REVIEW E 78 2008, 011502

5. Strubbe F., Beunis F., Marescaux M., Verboven B., Neyts K., Applied Physics Letters 93 2008, 254106

6. F. Strubbe, A.R.M. Verschueren, L.J.M. Schlangen, F. Beunis and K. Neyts, Journal of Colloid and Interface Science 300 2006, 396 